\title{
PROJETO DE MICRODRENAGEM DE ÁGUAS PLUVIAIS VIA TECNOLOGIA BIM
}

\section{Mariana Higashi Sakamoto (Bolsista), Prof. Dr. José Anderson do Nascimento Batista (Orientador).}

\section{Resumo}

Análise comparativa comparativa via aplicação BIM para a otimização do volume de escavação aplicado a microdrenagem de um loteamento residencial em Campinas.

\section{Palavras-chave: \\ Microdrenagem, otimização, modelagem da informação de construção (BIM)}

\section{Introdução}

Este trabalho propõe a otimização de volume de escavação em projetos de micro drenagem urbana desenvolvidos com o auxílio do software AutoCad Civil 3D e o plug-in Hydraflow Storm Sewers ${ }^{1}$ para uma amostra de loteamentos localizados no município de Campinas, SP. Foram comparados os desempenhos de dois métodos de dimensionamento da rede, o método convencional praticado na Engenharia e o assistido por BIM - Building Information Modelling. O objetivo deste experimento é testar a viabilidade técnica do BIM aplicado aos traçados de micro drenagem pela redução dos custos relacionados a obra e comparar com as práticas usuais da engenharia.

\section{Resultados e Discussão}

A área de estudo corresponde a um loteamento residencial de 11 hectares, no distrito de Barão Geraldo. As informações acerca da topografia, do traçado viário, do tipo de ocupação do solo e hidrografia da bacia hidrográfica foram coletadas da base de dados da SANASA. A equação de chuvas foi obtida da curva IDF de intensidade, duração e frequência por Vieira².

O posicionamento das bocas de lobo e consequente traçado das redes foram estabelecidos pela técnica dos Pontos de Saturação das sarjetas, resultando no lançamento de duas redes. Além disso, a declividade, diâmetro e elevação das galerias foram dimensionados para atender as recomendações das normas técnicas ${ }^{3}$, incluindo cobrimento mínimo, velocidade do escoamento, lâmina d'agua, diâmetro e alinhamento entre tubos.

A Figura 1 representa um trecho da rede em perfil. As linhas verdes indicam a topografia do terreno e as azuis, as estruturas da rede de drenagem. Enquanto a linha vermelha indica a linha de energia, a tracejada mostra a linha piezométrica.

Figura 1. Trecho da rede em perfil pelo Hydraflow.

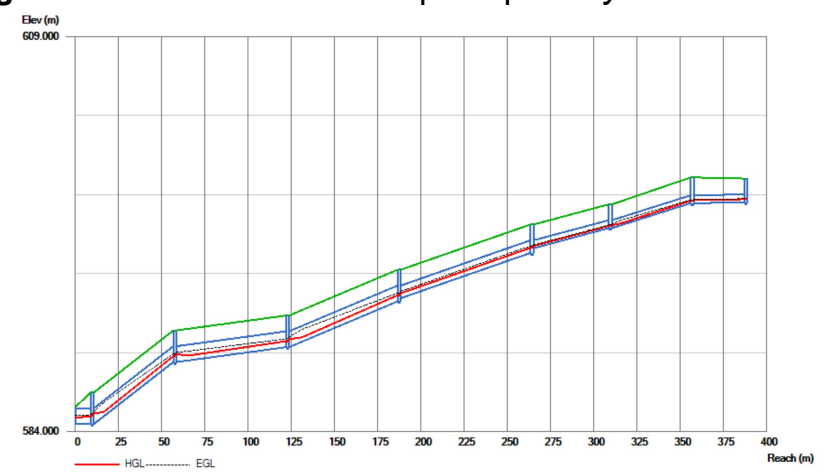

No método convencional, limitou-se a declividade das galerias a adotar a mesma do terreno; e os diâmetros dos tubos a adotar o menor diâmetro comercial que atendia aos requisitos de projeto.

No método com a aplicação do BIM, foi adotado um método iterativo, com o auxílio do Hydraflow, que minimizava o volume de escavação por trecho (no sentido da montante a jusante), variando sua declividade e diâmetro. Essas variáveis apresentam uma influência inversamente proporcional na velocidade do escoamento das aguas pluviais e, além disso, o volume de escavação varia linearmente com elas. Isto atrelado às restrições de projeto permitiu com que o processo convergisse rapidamente para a solução ótima.

A tabela 1 mostra os resultados obtidos do volume de escavação linear para cada método. Obtendo-se uma redução no volume em $63 \%$ e $41 \%$ respectivamente para as redes Norte e Sul.

Tabela 1. Volume de Escavação linear em $\mathrm{m}^{3} / \mathrm{m}$.

\begin{tabular}{|c|c|c|}
\hline Rede & Método Convencional & Método com BIM \\
\hline Norte & 608,4 & 388,5 \\
\hline Sul & 2100,1 & 858,85 \\
\hline
\end{tabular}

\section{Conclusões}

A utilização do BIM permitiu simular hidraulicamente alternativas para a configuração da rede, agregando informações importantes para otimizar o volume escavado a cada iteração, que sem o uso da tecnologia seria inviável pelo tempo demandado ao projetista.

As vantagens da dissminação no BIM na microdrenagem se estendem, além da economia no resultado final, também nas fases de projeto. $O$ fluxo de informações agiliza e integra os processos.

Um projeto de micro drenagem urbana eficiente é fundamental para o planejamento urbano com vista à eficiência do orçamento de obras bem como à minimização de riscos às populações ${ }^{4}$.

\footnotetext{
${ }^{1}$ Smith, W.C. Intelligent Hydrology with AutoCAD Civil 3D - Lab. Autodesk University 2015. Disponível em: $<$ http://au.autodesk.com/au-online/classeson-demand/class-catalog/classes/year-2015/autocad-civil-3d/ci11309-l>

Acesso em 24 de abril de 2018

${ }^{2}$ VIEIRA, D. B. - Análise das máximas intensidades de chuvas na cidade de Campinas. In: IV Simpósio Brasileiro de Hidrologia e Recursos Hidricos, ABRH, Fortaleza - CE. 1981. Anais I, pp. 375-386.

${ }^{3}$ INSTITUTO DE PESQUISAS HIDRAULICAS (IPH/UFRGS). Plano diretor de Drenagem Urbana - Manual de Drenagem Urbana. Vol. IV. Porto Alegre, 2005.

4 AZHAR, SALMAN \& HEIN, MICHAELl \& SKETO, BLAKE. Building Information Modeling (BIM): Benefits, Risks and Challenges. 2019
} 